\title{
Prediction of springback in V-die air bending process by using finite element method
}

\author{
Tomasz Trzepiecinski ${ }^{1, *}$, and Hirpa G. Lemu ${ }^{2}$ \\ ${ }^{1}$ Rzeszow University of Technology, Department of Materials Forming and Processing, al. Powst. \\ Warszawy 12, 35-959 Rzeszów, Poland \\ ${ }^{2}$ University of Stavanger, Department of Mechanical and Structural Engineering, N-4036 Stavanger, \\ Norway
}

\begin{abstract}
Springback phenomenon affects the dimensional and geometrical accuracy of the bent parts. The prediction of springback is a key problem in sheet metal forming. The aim of this paper is the numerical analysis of the possibility to predict the springback of anisotropic steel sheets. The experiments are conducted on $40 \times 100 \mathrm{~mm}$ steel sheets. The mechanical properties of the sheet metals have been determined through uniaxial tensile tests of samples cut along three directions with respect to the rolling direction. The numerical model of air V-bending is built in finite element method (FEM) based ABAQUS/Standard 2016.HF2 (Dassault Systemes Simulia Corp., USA) program. The FEM results were verified by experimental investigations. The simulation model has taken into consideration material anisotropy and strain hardening phenomenon. The results of FEM simulations confirmed the ability of numerical prediction of springback amount. It was also found that the directional microstructure of the sheet metal resulted from rolling process affects the elastic-plastic deformation of the sheets through the sample width.
\end{abstract}

\section{Introduction}

Springback is considered as the main problematic phenomenon that affects the quality of bent elements where the material undergoes geometrical changes. It occurs because of the elastic relief from the bending moment imparted to the sheet metal during forming [1]. Springback can be seen as an elastically-driven change of a shape of a deformed product which takes place during removal of the external loads that brought about the elastic deformation. Springback plays an important role in tooling and process designs in many industries, e.g., automotive industry, aerospace industry, and machine-building industry. [2-4]:

The amount of springback during unloading depends on three main groups of parameters

- technological: speed of deformation, lubrication, punch holding time, punch radius, repeat bending, and temperature,

- geometrical: bending radius, sheet thickness, sheet width,

\footnotetext{
*Corresponding author: tomtrz@prz.edu.pl
} 
- material: material type, Young's modulus, yield stress, microstructure of the material, orientation of bending line according to the rolling direction of the sheet, ratio of yield stress to tensile strength.

In order to have better understanding of the springback phenomenon and the parameters influencing it, a number of research works have been previously reported. The effect of punch tip radius, sheet thickness, and sheet orientation on springback of CK67 steel sheets in Vbending process was reported by Bakhshi-Jooybari et al. [5]. They observed that springback decreases with an increase of sheet thickness. Furthermore, they concluded in their study that there exists no effect of bending angle according to rolling direction on the springback. Meinders et al. [6] investigated the effect of the geometry of punch and die on springback defect and indicated that the bulk material affects springback in bending operation. Blank holder force and effect of lubrication in springback analysis are studied by Chirita [7] and it was found that the greater the friction, the smaller becomes the springback. The effect of pad force and elevated temperature of sheet metal were studied by Duflou and Aerens [8]. It was experimentally demonstrated that local preheating of $25 \mathrm{~mm}$ thick steel plates result in reduction of bending force by $55 \%$. Chalal et al. [9] observed that springback decreases almost linearly with an increase of sheet tension.

Among many parameters affecting springback, the Young's modulus is the main material property that influences the value of elastic springback of the material. In the analysis of sheet metal forming, it is common practice to assume that the elastic modulus remains constant. However, experimental investigations of Lems [10] revealed that elastic constants of a material may change during the plastic deformation. It was shown by Cleveland and Ghosh [11] and Yang et al. [12] that for steel materials the Young's modulus can decrease with plastic straining by up to $20 \%$ of its initial value. Additionally, Lems [10] and Morestin and Boivin [13] also indicated experimentally that the elastic modulus recovers to its initial value with time. According to Cleveland and Ghosh [11] and Wang et al. [14] the reduction of the Young's modulus can be seen as an extra nonlinear component of the total springback strain which is strongly dependent on the crystallographic texture evolution.

In many years, various experimental tests have been developed to study springback in sheet metal forming. The most popular and commonly used methods include: cylindrical bending, U-bending [15], V-bending [16], double-curvature forming [17], flanging [18] and other simple bending-reverse bending experimental methods [19].

Several analitycal methods are available for the prediction of springback [20]. The commonly used analytical models predict springback based on elastic unloading from a bending moment [2]. These models require the knowledge of the stress distribution within the part under bending. Other residual differential strain models only require the stress state on the outer and inner surfaces of the sheet.

The mechanical properties of anisotropic sheets depend on the chosen direction within the specimen. Accordingly, rolling process creates different features of the material microstructure and hence it results in planar anisotropy of sheet metals [21]. To account for these and other influencing factors and make nearly accurate numerical modelling of springback in sheet metal forming, finite element method (FEM) is commonly used. However, the achievable accuracy mostly requires the knowledge of sheet material model description. Thus, the selection of an appropriate material model is one of the crucial steps in preparing a FEM model for analysis of sheet bending [2].

Generally, material modelling can be divided into two parts: yield function and hardening law. Widely used yield function which can represent the behaviour of anisotropic steel sheets is the quadratic Hill' 48 criterion [22]. To ensure an accurate springback prediction it is necessary to use hardening models which are able to describe the effects of strain hardening. Shu and Hung [23] reported that poor representation of the Bauschinger effect is one of the main reasons for poor springback prediction accuracy. Considering the contact behaviour, 
the Lagrange multiplier method and the penalty method are the main methods used to incorporate the contact conditions into a finite element formulation $[24,25]$. The choice of an element type is also very important for accurate numerical prediction of springback using FE analysis. Depending on the geometry of the sheet metal specimen, different types of elements can be used to discretise the workpiece, i.e. 2D plane strain, shell, solid or solidshell. To speed up the analysis time, shell elements are commonly used because they provide better accuracy of springback prediction, compared with 3D solid elements.

In this paper, the results of experimental and numerical investigations of springback of deep-drawing steel sheets commonly used in automotive industry are presented. Air bending experiments were carried out in a designed $90^{\circ} \mathrm{V}$-die. The numerical model of air V-bending is built in FEM-based ABAQUS/Standard program and material anisotropy and strain hardening phenomenon have taken into consideration.

\section{Material and method}

The experiments are conducted on $40 \mathrm{~mm} \times 100 \mathrm{~mm}$ DC04 steel sheets cut under the angle of $0^{\circ}$ and $90^{\circ}$ with respect to the rolling direction of the sheet. The mechanical properties of the sheet metals (Table 1) have been determined through uniaxial tensile tests of samples cut along three directions with respect to the rolling direction. The average values of mechanical parameters are determined using the formula:

$$
X_{a v}=\frac{X_{0}+2 X_{45}+X_{90}}{4}
$$

where: $\mathrm{X}$ - the mechanical parameter, the subscripts denote the orientation of the sample with respect to the rolling direction of sheet.

The anisotropy of plastic behaviour of sheet metals is characterized by the Lankford's coefficient $r$, which is determined by uniaxial tensile tests. Hollomon law describes the value of parameters of strain hardening phenomena as follows:

$$
\sigma=C \cdot \varepsilon^{n}
$$

where: $\sigma-$ stress, $\varepsilon$ - plastic strain, $\mathrm{C}-$ strain hardening coefficient, $\mathrm{n}-$ strain hardening exponent.

The values of the parameters $C$ and $n$ are determined from the logarythmic true stress true strain plot by linear regression. The mean value of $n$ exponent for the whole range of strain is usually assumed in the numerical simulations. Upon derivation of Eq. (2), the following expression for the strain hardening exponent is obtained:

$$
n=\frac{d \sigma}{d \varepsilon} \frac{\varepsilon}{\sigma}
$$

Based on the results of the uniaxial test, it was found that the value of the exponent $n$ depends on micro-structure texture of the material and changes with effective strain value.

Air bending experiments were carried out in a designed semi closed $90^{\circ} \mathrm{V}$-die (Fig. 1). The die assembly consists of a die with $\mathrm{Rd}=10 \mathrm{~mm}$ rounded edge, and a punch with a nose radius of $\mathrm{Rs}=10 \mathrm{~mm}$. During the tests, three parameters were measured: bending force FB, punch bend depth under loading fl and punch bend depth under unloading ful (Fig. 2). The values of these parameters were registered by QuantumX Assistant V.1.1 program for processing the signals of both force and punch stroke transducers. The amount of springback was then evaluated as: 


$$
K=f_{U L} / f_{1}
$$

Table 1. Mechanical properties of the tested sheets.

\begin{tabular}{|c|c|c|c|c|c|}
\hline Orientation & $\begin{array}{c}\text { Yield stress } \\
\boldsymbol{\sigma}_{\boldsymbol{y}} \\
{[\mathbf{M P a}]}\end{array}$ & $\begin{array}{c}\text { Ultimate tensile } \\
\text { strength } \\
\boldsymbol{\sigma}_{\boldsymbol{m}} \\
{[\mathbf{M P a}]}\end{array}$ & $\begin{array}{c}\text { Strain } \\
\text { hardening } \\
\text { coefficient } \\
\boldsymbol{C} \text { [MPa] }\end{array}$ & $\begin{array}{c}\text { Strain } \\
\text { hardening } \\
\text { exponent } \\
\boldsymbol{n}\end{array}$ & $\begin{array}{c}\text { Lankford's } \\
\text { coefficient } \\
\boldsymbol{r}\end{array}$ \\
\hline $0^{\circ}$ & 182.1 & 322.5 & 549.3 & 0.214 & 1.751 \\
\hline $45^{\circ}$ & 196 & 336.2 & 564.9 & 0.205 & 1.124 \\
\hline $90^{\circ}$ & 190 & 320.9 & 555.2 & 0.209 & 1.846 \\
\hline Average value & 191.02 & 328.9 & 558.57 & 0.208 & 1.461 \\
\hline
\end{tabular}

where: ful - punch bend depth under unloading, $\mathrm{fl}$ - punch bend depth under loading.

Samples cut in the rolling $\left(0^{\circ}\right)$ and transverse $\left(90^{\circ}\right)$ to the rolling direction were used in $\mathrm{V}$-bending test. The resultant of springback coefficient for each experiment is then obtained by averaging the values of springback for the three experiments.

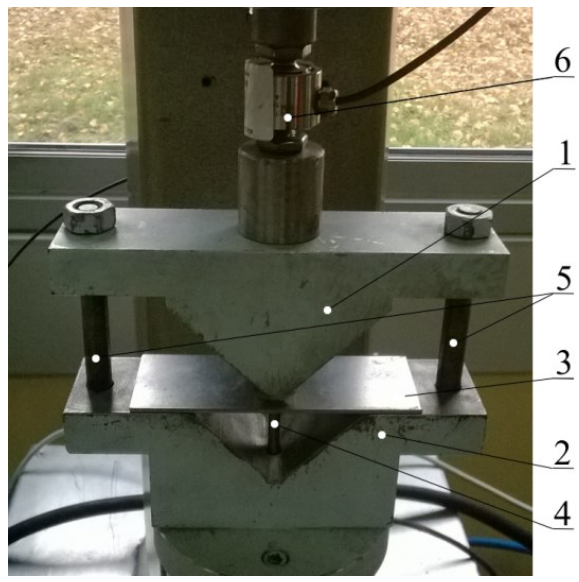

Fig. 1. The experimental setup: 1 - punch, 2 - die, 3 - sample, 4 - punch stroke controller, 5 - guide columns, 6 - force transducer.

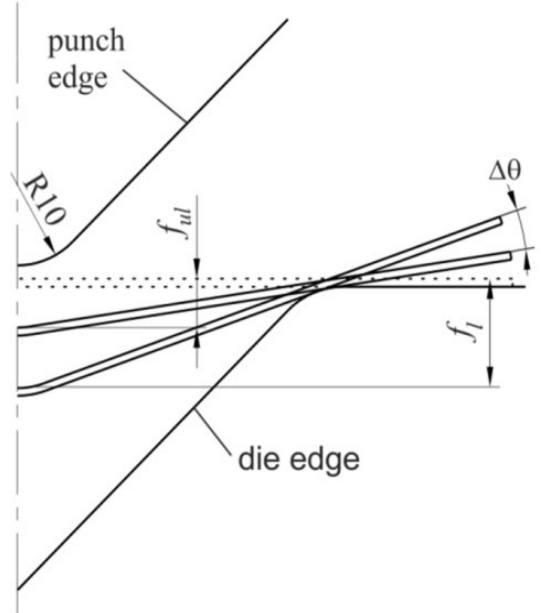

Fig. 2. The schematic of measurement of springback

\section{Numerical model}

The geometry of the blank and tools corresponds to the experimental set-up (Fig. 1). The analytical discrete rigid tools are meshed using 4-node 3-D bilinear rigid quadrilateral R3D4 elements. The blank was modeled with 4-node quadratic, doubly curved shell elements S8R [26] with five integration points through sheet thickness direction. Five integration points were employed because they are accurate to obtain satisfactory results [27]. The S8R shell type element is intentionally applied for the analysis of sheet metal forming processes [28], and this type of element accounts for the change of thickness in its output variables, unlike solid and plane strain elements. The blank model is composed of the different number of elements to analyze the mesh sensitivity. The tools consist of 9586 elements. The used 
boundary conditions allow moving the punch at Z-direction (Fig. 3). To determine an optimal mesh size the numerical analyses were carried out for four meshes with the number of elements: 84, 280, 1120 and 4400. Furthermore, the sensitivity analysis of the mesh size was done for four punch strokes $\mathrm{f}_{\mathrm{g}}: 3,6,12$ and $18 \mathrm{~mm}$. After getting certain stroke, the punch is moved back and the springback was measured. In air V-bending process, there exists linear contact between the sheet and samples so the friction coefficient influences the springback amount in small scale. The friction coefficient between the sheet metal and tools was assumed to be $0.01[29]$.

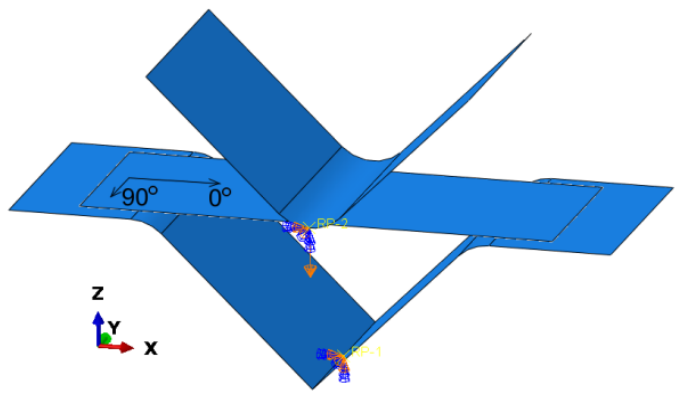

Fig. 3. Boundary conditions in V-bending model of the sample cut along the sheet rolling direction

The elastic behavior is specified in numerical simulations by the value of Young's modulus, $\mathrm{E}=210 \mathrm{GPa}$, and of Poisson's ratio $v=0.3$. In the numerical model, the anisotropy of the material has been established using Hill (1948) [22] yield criterion (Eq. 5) with hardening behavior using Hollomon power-type law (Eq. 2).

$$
\bar{\sigma}^{2}=F\left(\sigma_{22} \neg \sigma_{33}\right)^{2}+G\left(\sigma_{33} \neg \sigma_{11}\right)^{2}+H\left(\sigma_{11} \neg \sigma_{22}\right)^{2}+2 L \sigma_{23}^{2}+2 M \sigma_{31}^{2}+2 N \sigma_{12}^{2}
$$

where, $\bar{\sigma}$ is the equivalent stress, and indices $1,2,3$ represent the rolling, transverse and normal direction to the sheet surface. Constants F, G, H, L, M and N define anisotropy state of material and can be computed based on Lankford's coefficients [22].

The major advantage of the Hill (1948) function is that it gives an accurate description of yielding of steel sheets [30].

\section{Results and discussion}

Increasing the number of elements stabilizes the springback (Fig. 4) measured as the difference between punch bend depth under loading $f_{l}$ and unloading $f_{u l}$ :

$$
K_{S}=f_{1} \neg f_{u l} \quad[\mathrm{~mm}]
$$

The error of springback prediction $K_{s}$ (Table 2) is determined using the formula:

$$
E_{S}=100 \neg \frac{100\left(f_{l}^{a+1} \neg f_{u l}^{a+1}\right)}{f_{l}^{a} \neg f_{u l}^{a}}[\%]
$$

where a is the level of the mesh density I, II, III and IV corresponded to the number of elements: 84, 280, 1120 and 4400, respectively.

Next, the absolute mean error $\mathrm{E}_{\mathrm{s}}^{\mathrm{abs}}$ is determined: 


$$
\mathrm{E}_{\mathrm{s}}^{\mathrm{abs}}=\frac{1}{4} \sum_{\mathrm{i}=1}^{\mathrm{i}=4}\left|\mathrm{E}_{\mathrm{s}}^{(\mathrm{i})}\right|[\%]
$$

where $i$ is the level of punch stroke $i=1,2,3$, and 4 corresponded to punch stroke $3,6,12$, and $18 \mathrm{~mm}$, respectively.

The error $E_{s}$ after increasing the number of elements from 1120 to 4400 is the smallest for all analysed mesh densities (Table 2).

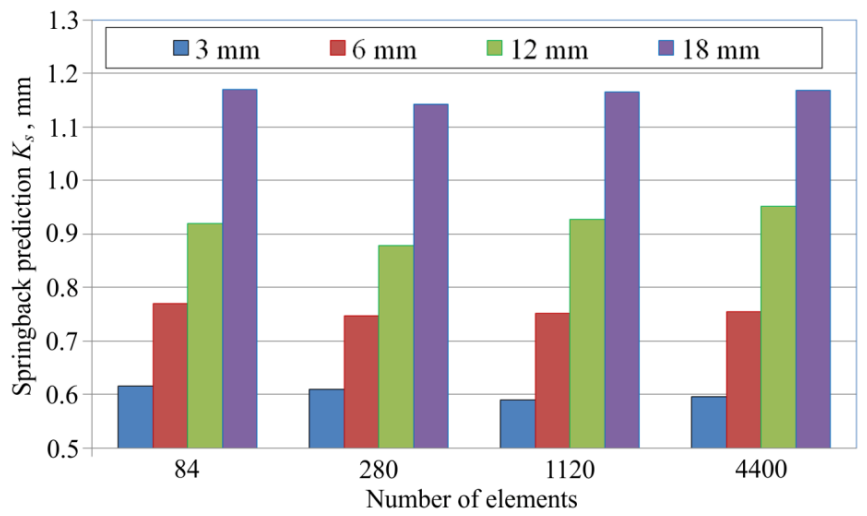

Fig. 4. Influence of the number of elements on amount of springback

Table 2. Error of springback prediction

\begin{tabular}{|c|c|c|c|}
\hline \multirow{2}{*}{$\begin{array}{c}\text { Punch stroke, } \\
\mathrm{mm}\end{array}$} & \multicolumn{3}{|c|}{$\begin{array}{c}\text { The springback prediction error for the change in the } \\
\text { number of elements } E_{s}, \%\end{array}$} \\
\cline { 2 - 4 } & $84 \rightarrow 280$ & $280 \rightarrow 1120$ & $1120 \rightarrow 4400$ \\
\hline 3 & -0.81 & -3.44 & 1.01 \\
\hline 6 & -2.98 & 0.52 & 0.41 \\
\hline 12 & -4.45 & 4.35 & 2.79 \\
\hline 18 & -2.3 & 1.93 & 0.33 \\
\hline Absolute mean error & 2.64 & 2.56 & 1.14 \\
\hline
\end{tabular}

The absolute mean error value $\mathrm{E}_{\mathrm{s}}^{\mathrm{abs}}$ for all analysed punch strokes $f_{g}$ is equal to $2.64 \%$ (after increasing number of elements from 84 to 280 ), 2.56\% (from 280 to 1120 ) and $1.14 \%$ (from 1120 to 4400 ). We also assume the accepted $E_{s}^{a b s}$ value of $1.5 \%$. So, the number of elements 1120 is acceptable and then numerical models considered this number of elements.

Springback intensity is influenced by the orientation of the sample in terms of symmetric plane of the punch. It is conceivable that sample orientation due to rolling direction produces variations of the elastic-plastic properties of the sheet metal and residual stress after sample unloadning (Fig. 4). Although the distribution of the residual stress is similar for both analysed orientations, the difference in the value of maximum stress depends on punch depths and the difference is in the range of 3 - $5 \mathrm{MPa}$. The sheets produced in cold-rolling process exhibit directional elongation of grains in the rolling direction. According to Eq. (4), the high springback of the material denotes the lower values of springback coefficient. So, the samples bent parallel to the sheet rolling direction $\left(0^{\circ}\right.$ in figure 3$)$ exhibit higher value of springback. The variation of springback coefficient $(K)$ value with the relative bending depth $w / f_{l}$ (where $w$ is bending length of a sample) is analyzed as depicted in figure. 5. As shown in the figure, the $K$ value and $w / f_{l}$ have almost linear dependence. The differences in $K$ value between the results of both orientations of the sample are similar for all analyzed relative bending depths. However, the numerical models in all cases overpredict the springback coefficient value. 
This is because, in the case of $0^{\circ}$ rolling direction, during the draw bending process the grains are only subjected to tensile or bending stresses, but in the case of $90^{\circ}$ rolling direction an important amount of deformation energy is used to change the orientation of grains [31]. The lower springback coefficient evaluated based on the punch depths under unloading and loading translates into higher value of springback angle $\Delta \theta$ (Fig. 2). It is understood that the springback angle is a function of yield strength to Young's modulus $(\sigma y / E)$ [32], which is higher for transverse direction than rolling direction.
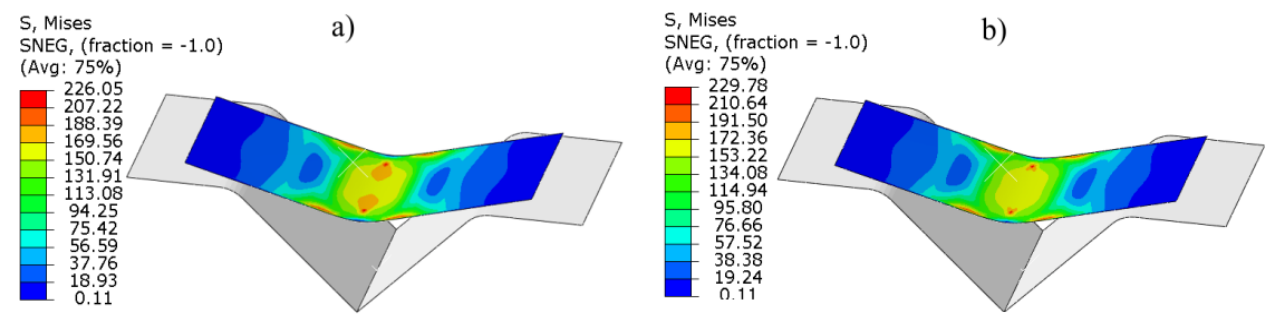

Fig. 4. The von Mises stress distribution after unloading samples oriented at $0^{\circ}$ (a) and $90^{\circ}$ (b), punch depth under loading $12 \mathrm{~mm}$

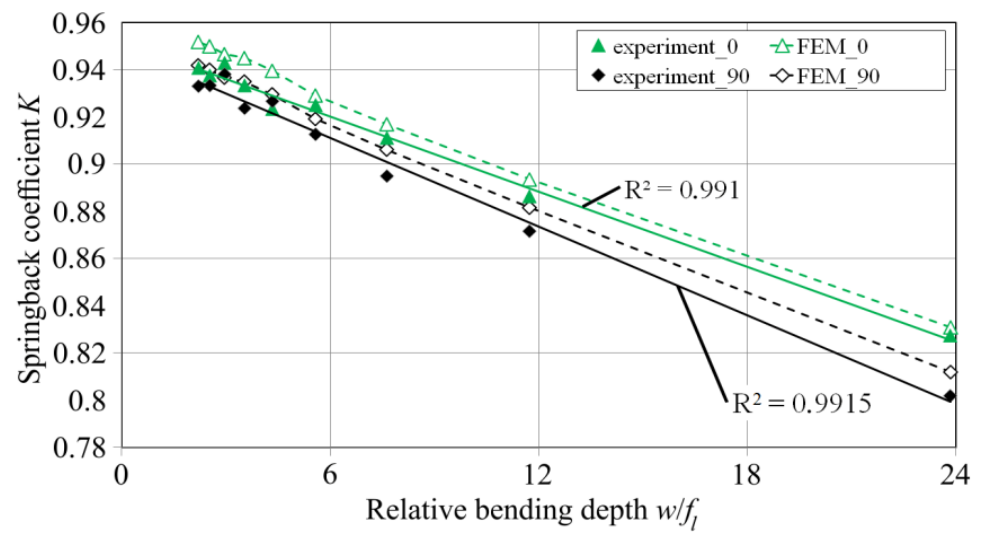

Fig. 5. Comparison of springback coefficient value determined experimentally and by FEM approach

\section{Conclusions}

The results of experimental and numerical investigations of springback of deep-drawing steel sheets commonly used in automotive industry are presented in this paper. The results indicated that orientation of the sample cut from anisotropic steel sheet has a great influence on springback. The test specimens were cut in the rolling direction $\left(0^{\circ}\right)$ and transverse direction $\left(90^{\circ}\right)$ of the sheet metal and the blank cut along the transverse direction exhibits greater springback than the blank cut in the rolling direction. These results were found both experimentally and by FE models. However, in all analyzed case, numerical models overpredict the springback coefficient value. A decreasing springback coefficient is observed when the relative bending depth $\left(w / f_{i}\right)$ increases. The analysis of variation of springback coefficient value shows almost linear dependence between the spring coefficient $(K)$ value and relative bending depth. In the case of high values of bending depth $\left(f_{l}\right)$, there is an increasing plastic zone through the sheet thickness in the middle part of the sample that influences the low values of springback coefficient. 


\section{References}

1. H.M. Huang, S.D. Liu, S. Jiang, J. Eng. Mater. Tech. 123 (2001)

2. I.A. Burchitz, Improvement of springback prediction in sheet metal forming (PrintPartners Ipskamp, Enschede, 2008)

3. I.A. Choudhury, V. Ghomi, Proc. Inst. Mech. Eng. B: J. Eng. Manu. 288 (2014)

4. H.K. Yi, D.W. Kim, C.J. Van Tyne, Y.H. Moon, Proc. Inst. Mech. Eng. C: J. Mech. Eng. Sci. $222(2008)$

5. M. Bakhshi-Jooybari, B. Rahmani B, V. Daeezadeh, A. Gorji, Mater. Des. 30 (2009)

6. T. Meinders, I.A. Burchitz, M.H.A. Bonte, R.A. Lingbeek, Int. J. Mach. Tool. Manu. 48 (2008)

7. B. Chirita, Arch. Civ. Mech. Eng. 3 (2003)

8. J.R. Duflou, R. Aerens, CIRP Ann: Manuf. Tech. 55 (2006)

9. H. Chalal, R. Sever-Gabriel, B. Tudor, Int. J. Mech. Sci. 59 (2012)

10. W. Lems, The change of Young's modulus after deformation at low temperature and its recovery (Delft University of Technology, Delft, 1963)

11. R.M. Cleveland, A.K. Ghosh, Int. J. Plast. 18 (2002)

12. M. Yang, Y. Akiyama, T. Sasaki, J. Mater. Process. Tech. 151 (2004)

13. F. Morestin, M. Boivin, Nuclear Eng. Des. 162 (1996)

14. J.F. Wang, R.H. Wagoner, W.D. Carden, D.K. Matlock, F. Barlat, I. J. Plast. 20 (2004)

15. D.K. Leu, Mater. Des. 94 (2016)

16. W. Xiong, W. Wang, M. Wan, X. Li, J. Manu. Process. 19 (2015)

17. P. Xue, T.X. Yu, E. Chu, J. Mater. Process. Tech. 89-90 (1999)

18. H. Livatyali, H.C. Wu, T. Altan, J. Mater. Process. Tech. 120 (2002)

19. J.T. Gau, G.L. Kinzel, Int. J. Mech. Sci. 43 (2001)

20. D.K. Leu, J. Mater. Process. Tech. 66 (1997)

21. F. Barlat, D. Banabic, O. Cazacu. Anisotropy in sheet metals. In: D.Y. Yang, S.I. Oh, H. Huh, Y.H. Kim (Eds.) Proc. ${ }^{\text {th }}$ Int. Conf. And Workshop on Numerical Simulation of 3D Sheet Forming Processes NUMISHEET 2002, 515 - 524, (Jeju Island, Korea, 2002)

22. R. Hill, Proc. Royal Soc. Lond. 193 (1948)

23. J.S. Shu, C. Hung, Int. J. Mach. Tool Manu. 36 (1996)

24. B.D. Carleer, Finite element analysis of deep drawing (University of Twente, Enschede, 1997)

25. G. Kloosterman, Contact methods in finite element simulations (University of Twente, Enschede, 2002)

26. F. Song, H. Yang, H. Li, M. Zhan, G. Li, Chinese J. Aeronaut. 26 (2013)

27. M. Hudovernik, D. Staupendahl, M. Gharbi, M. Hermes, A.E. Tekkaya, K. Kuzman, J.M. Slabe, Stroj. Vest. -J. Mech. Eng. 59 (2013)

28. H.G. Lemu, T. Trzepieciński, Stroj. Vest.- J. Mech. Eng. 59 (2013)

29. W. Frącz, F. Stachowicz, Manu. Ind. Eng. 2 (2008)

30. T. Trzepieciński, H.L. Gelgele, Int. J. Mater. Form. 4 (2011)

31. A. Albut, G. Brabie, Arch. Civ. Mech. Eng. 6 (2006)

32. R. Narayanasamy, P. Padmanabhan, J. Manuf. Eng. 3 (2008) 